\title{
Intracoronary injection of autologous bone marrow-derived mononuclear cells in patients with large anterior acute myocardial infarction and left ventricular dysfunction: A 24- month follow up study
}

\author{
Skalicka $\mathrm{H}^{1}$, Horak $\mathrm{J}^{1}$, Kobylka $\mathrm{P}^{2}$, Palecek $\mathrm{T}^{1}$, Linhart $\mathrm{A}^{1}$, Aschermann $\mathrm{M}^{1}$ \\ 2nd Department of Internal Medicine, General University Hospital in Prague, Czech Republic. \\ skaldah@seznam.cz
}

\begin{abstract}
Objective and background: Despite the use of reperfusion therapies, outcomes in patients with large myocardial infarction (MI), late reperfusion and left ventricular (LV) dysfunction are poor. We investigated long-term safety and efficacy of intracoronary injections of autologous bone marrow-derived mononuclear cells (BMNCs). Methods: 27 patients with anterior MI (age 59 \pm 12 years, mean baseline LV ejection fraction (LVEF) $39 \pm 5 \%$ ), who underwent percutaneous coronary intervention 4-24 hours after the onset of symptoms, were randomly assigned either to intracoronary BMNCs injection ( $n=17$, BMNCs group, out of which 14 underwent long-term follow-up), or to standard therapy ( $n=10$, Control group). The LVEF, the LV end-diastolic and end-systolic volumes (LVEDV, LVESV) were assessed by echocardiography at discharge, Month 4 and 24 . Myocardial perfusion was assessed using SPECT at baseline and Month 4.

Results: At 24-month, there was no difference in rates of serious clinical events (36\% vs $50 \%, p=0.54)$. At Month 4 LVEF improved to similar extent in both groups (absolute change $+5.8 \%$ vs $+7.6 \%, p=0.75$ ), with similar infarct size reductions $(-10.9 \%$ vs $-12.2 \%, p=0.47)$. However, at Month 24 , LVEF further improved in BMNCs patients $(+12 \%$ vs $+8.5 \%, p=0.03)$. This effect resulted from a more pronounced reduction in LVESV $(-2.6 \mathrm{ml}$ vs $-1.8 \mathrm{ml}, \mathrm{p}=0.26)$ and a smaller increase in LVEDV $(+16.7 \mathrm{ml}$ vs $+17.9 \mathrm{ml}, \mathrm{p}=0.27)$ suggesting beneficial long-term effects on LV remodeling.

Conclusions: BMNCs injections in patients with MI and LV dysfunction were associated with a significant improvement of global LVEF during long term follow-up compared to standard therapy (Tab. 3, Fig. 1, Ref. 50). Full Text in PDF www.elis.sk.

Key words: bone marrow-derived mononuclear cells, myocardial infarction, remodeling, left ventricular ejection fraction.
\end{abstract}

Currently, up to $30 \%$ of patients with ST segment elevation myocardial infarction, usually those presenting later, show ongoing left ventricular (LV) remodeling with poor clinical outcomes, despite primary percutaneous coronary intervention (PCI) $(1,2)$. Cardiac transfer of bone marrow-derived stem and progenitor cells has been investigated as an adjunctive therapy to promote regeneration of the infarcted myocardium (3-5). Pilot clinical studies suggested that infusion of bone marrow or progenitor cells into the infarct-related coronary artery is feasible and may enhance recovery of the LV contractile function $(6,7)$. However, in randomized trials, the effects of BMNCs on LVEF and remodeling were

12nd Department of Internal Medicine, General University Hospital in Prague, Czech Republic, and 'Institute of Hematology and Blood Transfusion, Prague, Czech Republic

Address for correspondence: H. Skalicka, MD, Cardiocenter, 2nd Department of Internal Medicine - Cardiology, General University Hospital in Prague, U nemocnice 2, CZ-128 08 Prague, Czech Republic.

Phone/Fax: +420.2 .24962605$

Acknowledgement: This study was supported by the research grant IGA 8225-3 and by the Charles University in Prague Research Project MSM 0021620817 awarded by the Czech Ministry of Education, Youth and Physical Education. controversial (8-11), some studies reporting enhanced recovery of LVEF (12-14), which was not confirmed in other studies (11, 14). Since the LVEF reduction remains the major predictor of a poor outcome even in the era of PCI (15), enhanced recovery of the LV contractile function resulting from the bone marrow cells implantation might be beneficial especially in patients with large infarctions. Therefore, we designed a randomized study to assess the safety and efficacy of intracoronary injection of autologous BMNCs in patients with large acute anterior myocardial infarctions who presented late and who were successfully treated with primary PCI. The short-term results of our study were not encouraging (16), showing no additional effects of the cellular therapy on the left ventricular function compared to the standard treatment, and lead to early termination of the study. However, little is known about potential long-term effects of this treatment modality. This report presents the results of the 24- month follow up study in our patients.

\section{Methods}

Patients

The study population consisted of 27 consecutive patients (age $59 \pm 12$ yrs; $81 \%$ were males, the mean baseline LVEF was 


\section{LVEF $(\%)$, - BMNCs group}

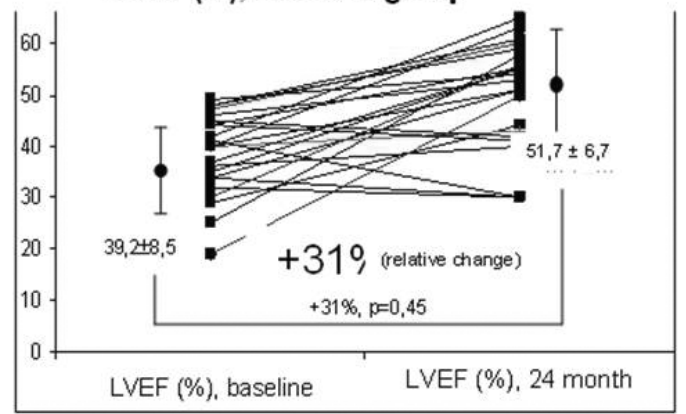

LVEF $(\%)$, - Control group
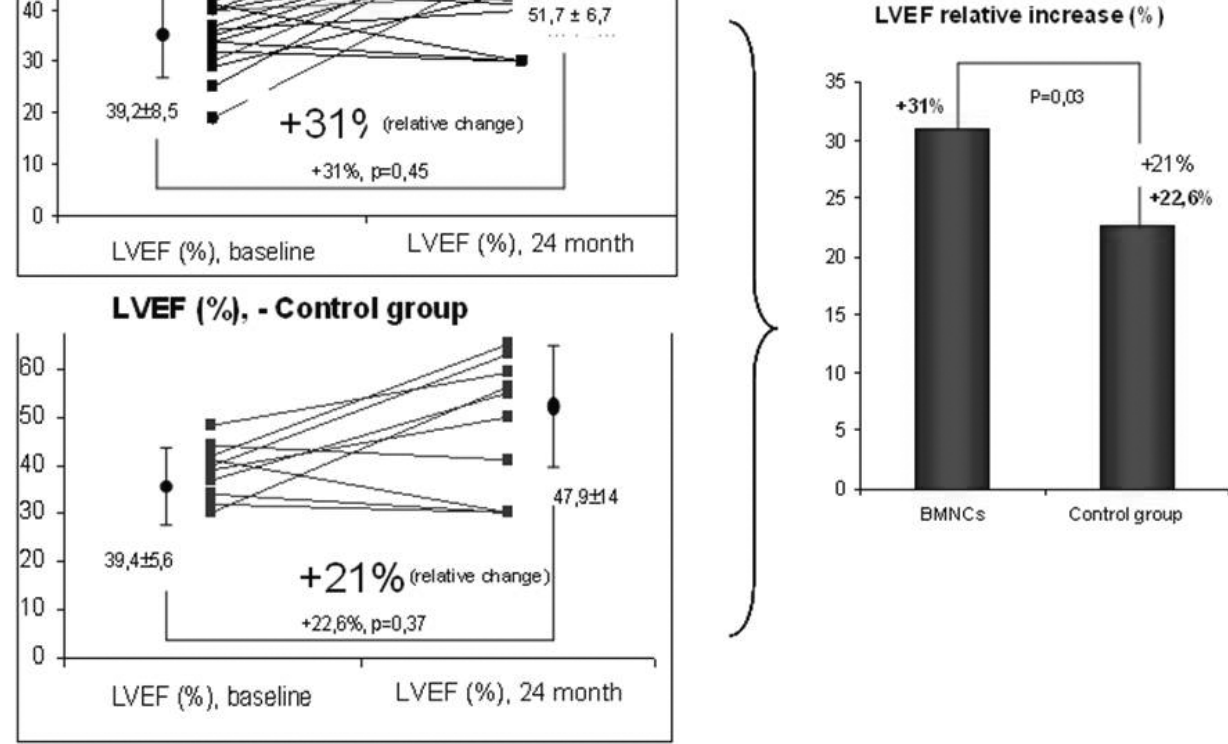

Fig. 1. Increase in the left ventricular ejection fraction in the BMNCs and the control group, a 24-month follow up study. Abbreviations: LVEF = left ventricular ejection fraction, $\mathrm{BMNCs}=$ bone marrow-derived mononuclear cell.

$39 \pm 5 \%$, range $19-45 \%$ ) with their first ST-segment elevation acute anterior myocardial infarction resulting from occlusion of the proximal left anterior descending coronary artery (LAD) and with TIMI flow grades $0-1$ at presentation, who were successfully treated with primary PCI with stent implantation. The patients were eligible for the study provided they had undergone the primary PCI 4 to 24 hours after the onset of symptoms and their echocardiogram performed 24 hours after the PCI procedure confirmed reduced LVEF (LVEF $\leq 50 \%$ ) with at least 3 akinetic segments in the LAD perfusion territory. The following were the exclusion criteria : age $\geq 80$ years, severe multivessel coronary artery disease requiring surgery, wall motion abnormalities in non-LAD territory, serious renal or hepatic disease, blood cells disorders, documented cancer or terminal illness. The study protocol was approved by Medical Ethical Committees of all the involved institutions and informed consents were obtained from all patients included in the study. The eligible patients were randomly, at a 2: 1 ratio, assigned either to a group with intracoronary BMNCs injection 4 to 11 days after PCI (BMNCs group) or to a standard medical therapy group (Control group). No bone marrow aspirations or sham injections were performed in the control group.

\section{Protocol}

The LV ejection fraction and volumes were assessed on echocardiography at discharge, at Month 4 and Month 24. In order to allow for recovery of the stunned myocardium, echocardiographic examinations performed at discharge served as baseline measurements for comparison with the follow-up echocardiographic examinations. Myocardial perfusion and glucose uptake was assessed by single photon emission computed tomography (SPECT) at patients discharge and at Month 4, using technetium-99m tetrofosmin and F18-fluorodeoxyglucose. Coronary angiography was repeated at Month 4. Cardiac troponin I, creatine kinase (CK) and its isoenzyme (CK-MB), as well as the white blood cell count and $\mathrm{C}$-reactive protein levels were assessed before and serially after the BMNCs transfer and at Month 4. In addition, Holter monitoring was performed before and after the BMNCs transplantation, at Month 1 and Month 4. The quality of life was assessed at Month 24 using a standard SF-36 questionnaire.

\section{BMNCs isolation and intracoronary injections (Fig. 1)}

In the BMNCs group, aspiration of BMNCs was performed by a staff hematologist 4 to 11 days after the index PCI. Bone marrow (BM) was harvested from the posterior superior iliac crest through multiple aspirations under analgesia sedation. Each BM aspiration was performed using a pre-filled syringe containing $1 \mathrm{ml}$ of an anticoagulant, to which $3 \mathrm{ml}$ of the bone marrow were harvested. The aspirates were transferred into the Bone Marrow Collection Kit with a Pre-Filter and Inline Filters (Baxter R4R2107, USA) and further processed in a closed blood bag system. Erythrocytes were separated through sedimentation with Gelofusine (Braun Melsungen, Germany) in the closed blood bag system. After the BMNCs isolation, the remaining plasma was removed, producing a BMNCs concentrate. The final BMNCs preparation was immediately transferred to a cath lab for intracoronary injection. The number of CD34+ cells was determined by a flow cytometry 
Tab. 1. Baseline characteristics.

\begin{tabular}{|c|c|c|c|}
\hline & BMNCs group $(\mathrm{n}=17)$ & Control group $(\mathrm{n}=10)$ & $\mathrm{p}$ value \\
\hline Male sex, n (\%) & $12(71)$ & $10(100)$ & NS \\
\hline Age, years & $61 \pm 14$ & $54 \pm 10$ & NS \\
\hline Hyperlipidemia, n (\%) & $5(30 \%)$ & $6(60 \%)$ & NS \\
\hline Smokers, n (\%) & $11(66)$ & $9(90 \%)$ & NS \\
\hline Diabetes mellitus, n (\%) & $5(29)$ & $2(20)$ & NS \\
\hline Hypertension, $\mathrm{n}(\%)$ & $7(42 \%)$ & $6(60 \%)$ & NS \\
\hline Systolic arterial blood pressure, baseline $(\mathrm{mmHg})$ & $129 \pm 33$ & $142 \pm 21$ & NS \\
\hline Diastolic arterial blood pressure, baseline $(\mathrm{mmHg})$ & $77 \pm 18$ & $82 \pm 21$ & NS \\
\hline Heart rate, baseline (bpm) & $83 \pm 19$ & $78 \pm 10$ & NS \\
\hline \multicolumn{4}{|l|}{ Extent of CAD } \\
\hline$\overline{\mathrm{SVD}, \mathrm{n}(\%)}$ & $7(41)$ & $6(60)$ & NS \\
\hline MVD, n (\%) & $10(59)$ & $4(40)$ & NS \\
\hline Time from the onset of pain to PCI, (min) & 315 (range $300-660$ ) & 330 (range $300-630$ ) & NS \\
\hline Maximum creatine kinase (ukat/l) & $59.5 \pm 12$ & $35 \pm 17$ & NS \\
\hline Maximum troponin (ug/l) & $152 \pm 22$ & $147 \pm 20$ & NS \\
\hline \multicolumn{4}{|l|}{ Killip class } \\
\hline $\mathrm{I} / \mathrm{II}, \mathrm{n}(\%)$ & $15(88)$ & $9(90)$ & NS \\
\hline III/IV, n (\%) & $2(12)$ & $1(10)$ & NS \\
\hline \multicolumn{4}{|l|}{ TIMI flow after PCI } \\
\hline Grade $2, \mathrm{n}(\%)$ & $4(23)$ & $2(20)$ & NS \\
\hline Grade $3, \mathrm{n}(\%)$ & $13(77)$ & $8(80)$ & NS \\
\hline Catecholamines, $\mathrm{n}(\%)$ & $2(12)$ & $1(10)$ & NS \\
\hline Left ventricular ejection fraction, $\%$ & $39 \pm 7$ & $39 \pm 4$ & NS \\
\hline \multicolumn{4}{|l|}{ Medication after PCI } \\
\hline Aspirin, n (\%) & $17(100)$ & $10(100)$ & NS \\
\hline Clopidogrel, n (\%) & $17(100)$ & $10(100)$ & NS \\
\hline ACE inhibitors/ AT1 blockers, n (\%) & $13(76)$ & $8(80)$ & NS \\
\hline B-blockers, n (\%) & $14(76)$ & $10(100)$ & NS \\
\hline Statins, n (\%) & $15(88)$ & $10(100)$ & NS \\
\hline
\end{tabular}

Abbreviations BMNCs = bone marrow-derived mononuclear cells, $\mathrm{CAD}=$ coronary artery disease, $\mathrm{MVD}=$ multivessel disease, $\mathrm{PCI}=$ percutaneous coronary intervention, $\mathrm{SVD}=$ single vessel disease, ACE inhibitors - angiotenzin converting enzyme inhibitors

analysis. Intracoronary transplantation of BMNCs was performed on the day of the harvest, as described above (6). In brief, 4 to $6 \mathrm{ml}$ portions of the BMNCs suspension were injected into the LAD through a central lumen of an inflated over-the-wire balloon catheter. Low-pressure balloon inflations were performed within the stented segment for up to 3 minutes or up to the maximum tolerated time, and were followed by 3 minute reperfusions. This step was repeated 5 to 7 times, depending on the BMNCs suspension volume.

\section{Echocardiography}

All the studies were performed with a commercially available system (Vivid 7, Vingmed-General Electric, Horten, Norway). The LV volumes (end-diastolic and end-systolic) and ejection fractions were assessed on apical 4-chamber and 2-chamber views using the biplane Simpson's method, the dimensions were measured along a standard parasternal long axis (17). All studies were stored in a digital (raw data) format, as well as on a S-VHS videotape for an off-line analysis. All the measurement data were the mean values of the data obtained for three consecutive beats. Digital baseline and follow-up echocardiographic recording were analyzed by echocardiography specialists blinded to the patient group assignment.

\section{Assessment of myocardial viability by SPECT}

Technetium-99m sestamibi (600 MBq) was injected intravenously to evaluate rest perfusion. After an intravenous injec- tion of glucose and insulin $(0.2 \mathrm{~g}$ of $40 \%$ glucose solution and 0.2 units of short-acting insulin), F18-fluorodeoxyglucose (400 $\mathrm{MBq}$ ) was injected intravenously to assess myocardial glucose uptake. Dual-isotope simultaneous image acquisition was performed 60 minutes after the F18-fluorodeoxyglucose injection, using high-energy 511-keV collimators. A symmetrical $15 \%$ energy window was preset on each side of the $140-\mathrm{keV}$ photon peak of technetium-99m sestamibi and 511-keV photon peak of F18fluorodeoxyglucose. The data were acquired over $180^{\circ}$ and stored in a $64 x 64$ computer matrix. The images were displayed in polar maps, which were normalized to a maximum activity (set at 100 $\%)$. To assess myocardial viability, the polar maps were divided into 16 segments (17). Segments with normal technetium-99m tetrofosmin myocardial perfusion and segments with perfusion defects but preserved or increased F18-fluorodeoxyglucose (perfusion-metabolism mismatch) perfusion were considered viable. Segments with a match (concurrently reduced perfusion and metabolism) were considered unviable.

\section{Statistical analysis}

Clinical results were analyzed based on the intention-to-treat principle. The continuous data are presented as the mean \pm standard deviation or the median and the interquartile range. The categorical data are presented as counts and percentages. The two-sided paired and unpaired Student's t-test or the Fisher's exact test were 
Tab. 2. Left ventricular global and regional systolic function, $L V$ volumes, dimension and infarction size at baseline, month 4 and month 24.

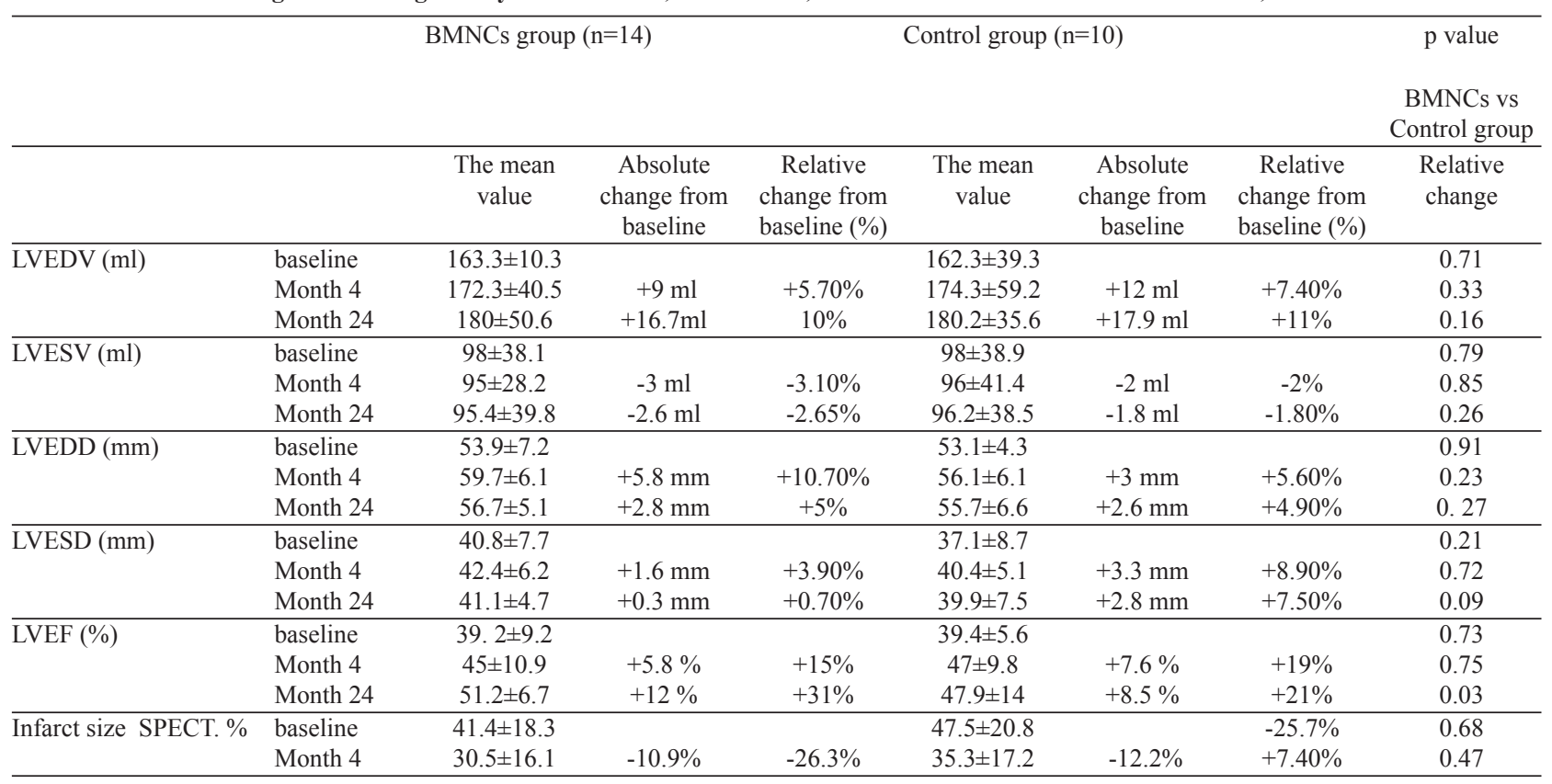

Abbreviations: LVEDV = left ventricular end-diastolic volume, LVESV = left ventricular end-systolic volume, LVEDD = left ventricular end-diastolic diameter, LVESD = left ventricular end-systolic diameter, LVEF = left ventricular ejection fraction, BMNCs - bone marrow-derived mononuclear cells, SPECT - Single photon emission computed tomography

used as appropriate. The repeated measures ANOVA model was used to test for responses of the examined parameters (measured at Month 0, 4 and 24). For all the tests, $\mathrm{p}<0.05$ was considered significant. All the statistical analyses were performed with the JMP statistical package.

\section{Results}

\section{Baseline characteristics}

A total of 27 patients were randomly assigned to either the BMNCs $(n=17)$ or the control $(n=10)$ group. Table 1 shows the baseline characteristics in both groups. The median time from the onset of pain to PCI was more than 5 hours. The majority of patients ( $89 \%$ ) were in the Killip I and II class at admission. The BMNCs group of patients were insignificantly older and had slightly higher prevalence of multivessel coronary artery disease than the controls. Other baseline characteristics including a degree of LV dysfunction were comparable between both groups. Similar percentages of patients in both groups showed the TIMI flow grade 3 after their PCI. The median time from PCI to the bone marrow harvest and intracoronary injection was 9 days (range, 4 to 11). On average, $171 \pm 48 \mathrm{ml}$ of bone marrow blood was harvested and processed to a final volume of $27 \pm 7 \mathrm{ml}$. The median number of injected BMNCs was $26.4 \times 10^{8}$ (range, $19.6 \times 10^{8}$ to $33.0 \times 10^{8}$ ). The viability of BMNCs ranged from 94 to $99 \%$. The median number of CD34+ cells was $1.3 \times 10^{6}$ (range, $1.1 \times 10^{6}$ to $1.4 \times 10^{6}$ ). The median total time of ischemia during repeated intracoronary BMNCs injections was $15 \mathrm{~min}$ (range, 11 to 18 ). Two patients, originally assigned to the BMNCs group, didn't receive active treatment because of complications, which occurred before the planned cell transfer. Both patients died during an early follow-up. One patient from the BMNCs group died for non-cardiac reasons 3 months later. Therefore, a total of 14 patients from the BMNCS group were available for the long-term outcome analysis.

\section{Functional outcome}

Table 2 shows baseline, Month 4 and Month 24 echocardiographic indices of the LV systolic function, the LV volumes and diameters according to the treatment assignment. LVEF improved to a similar extent in both groups at Month 4 (the absolute change was $+5.8 \%$ in the BMNCs group vs $+7.6 \%$ in the control group, the relative change was $+15 \%$ vs $+19 \%, p=0.75)$. Similarly, at Month 4, the infarction size was reduced to the same extent (the absolute change was minus $10.9 \%$ vs minus $12.2 \%$, the relative change was minus $26.3 \%$ vs minus $25.7 \%$, $\mathrm{p}=0.47$ ) in both groups. However, at Month 24, the left ventricular function continued to improve significantly in the BMNCs patients (the absolute change from the baseline was $+12 \%$, the relative change was $+31 \%$ ), while there was no further change in the control group (the absolute change was $+8.5 \%$, the relative change was $+21 \%$ ), $\mathrm{p}=0.03$. This effect resulted from a more pronounced decrease in LVESV (the absolute change was $-2.6 \mathrm{ml}$ vs $-1.8 \mathrm{ml}$, the relative change was $-2.65 \%$ vs. $-1.80 \%, p=0.26$ ) with a minor change in LVESD (the absolute change was $+0.3 \mathrm{~mm}$ vs $+2.8 \mathrm{~mm}$, the relative change was $+0.7 \%$ vs $+7.5 \%, \mathrm{p}=0.09$ ) and a smaller increase in LVEDV (the absolute change was $+16.7 \mathrm{ml}$ vs $+17.9 \mathrm{ml}$, the relative change was $+10 \% \mathrm{vs}+11 \%, \mathrm{p}=0.16$ ) and no change in LVEDD (the absolute change was $+2.8 \mathrm{~mm}$ vs $+2.6 \mathrm{~mm}$, the relative change was $+5 \%$ vs $+4.9 \%, p=0.27$ ) in the BMNCs group, suggesting a possible beneficial long-term effect on LV remodeling. 
Tab. 3. Safety and clinical outcome.

\begin{tabular}{lcc}
\hline & $\begin{array}{c}\text { BMNCs } \\
\text { group }(\mathrm{n}=17)\end{array}$ & $\begin{array}{c}\text { Control } \\
\text { group }(\mathrm{n}=10)\end{array}$ \\
\hline Cardiovascular mortality, n (\%) & $2(12)$ & 0 \\
Motality - non cardiovascular, n (\%) & $1(6)$ & 0 \\
Recurrent myocardial infarction, n (\%) & $1(6)$ & $1(10)$ \\
Heart failure hospitalization, n (\%) & $2(12)$ & $4(40)$ \\
Composite of death, myocardial infarction & $6(36)$ & $5(50)$ \\
and heart failure hospitalization, n (\%) & & \\
Restenosis, n (\%) & $2(12)$ & $4(40)$ \\
Revascularization, n (\%) & $4(24)$ & $4(40)$ \\
$\quad$ PCI, n (\%) & $2(12)$ & $2(20)$ \\
CABG, n (\%) & $2(12)$ & $2(20)$ \\
Documented ventricular tachycardia or & 0 & 0 \\
syncope, n (\%) & & $7(70)$ \\
NYHA I, II, n (\%) & $14(100)$ & $1.9 \pm 0.83$ \\
Mean NYHA class & $1.2 \pm 0.42$ & \\
\hline CABG $~$
\end{tabular}

CABG $=$ coronary artery bypass graft, $\mathrm{PCI}=$ percutaneous coronary intervention, NYHA - New York Heart Association classification

\section{Safety and clinical outcome (Tab. 3)}

The intracoronary BMNCs transfer was successful in all the enrolled patients. During the 24-month follow up, no significant difference was observed in the rates of serious clinical events between both groups (6 patients in the BMNCs group (36\%) vs. 5 patients $(50 \%)$ in the control group, $\mathrm{p}=0.54)$. Two patients developed serious complications before the cell transfer, which ultimately resulted in death. One patient had a ventricular septal rupture prior to the BMNCs harvest and was urgently operated. She died 3 months later because of severe heart failure. The other patient suffered from stent thrombosis with reinfarction before the BMNCs transfer. He underwent a complicated PCI procedure followed by $\mathrm{CABG}$, and died of sepsis and ARDS 2 weeks later. Early during the follow up period, 6 weeks after the BMNCs transfer, inoperable biliary carcinoma was diagnosed in 1 patient (asymptomatic at the time of index myocardial infarction) who died 2 months later. There was no difference in restenosis rates at Month 4 and in rates of late ischemic events, as well as in rates of late revascularization (4 patients in both groups). At Month 24, the mean NYHA class was better in the treated group $(1.2 \pm 0.42$ vs. $1.9 \pm 0.83, \mathrm{p}=0.04)$, however, there were no significant differences in QOL SF 36 parameters between the groups.

\section{Discussion}

This randomized study evaluated safety and efficacy of intracoronary injections of autologous

BMNCs in patients with large acute anterior myocardial infarction and late presentation, who were successfully treated with primary PCI. Despite the prior successful PCI of the infarct-related artery, such patients are at greatest risk of unfavorable post- infarction LV remodeling, which is a major cause of late, infarct- related heart failure events and death (18). The principal outcome of this study is the finding that although at Month 4 the intracoronary infusion of BMNCs did not appear to enhance recovery of the LVEF nor to reduce the LV volumes and the infarction size in the treatment group , compared to the control group, the long-term follow up analysis of the LV function demonstrated favorable changes in the BMNCs group, including a more pronounced decrease in LVESV and reduced LV dilatation, which resulted in significant ejection fraction improvements. These findings suggest a possible long-term beneficial effect on the LV remodeling.

\section{Clinical effects of BMNCs in acute myocardial infarction}

The possibility of improved myocardium regeneration and improvement of its function after the SCs application has been demonstrated in a number of experimental settings on various animal models $(5,19-22)$. Early, non- randomised clinical studies showed enhanced recovery of the LV contractile function after intracoronary infusion of BMNCs (23-26). However, results of randomised studies are more controversial. Whereas some studies showed a minor positive effect on recovery of the LV contractile function $(6,27-29)$, other studies failed to confirm these results $(11,30)$. Similarly, there were no consistent outcomes to demonstrate infarction size reduction effects $(9,30-32)$. In the largest study so far (33), patients assigned to the BMNSc group showed a moderate, but significant gain in the LV ejection fraction, compared to the controls. The results and conclusions of these studies are difficult to interpret, because of heterogeneity of the patient populations and the study designs used. The meta-analysis by Martin-Randon et al (34) can be considered the most comprehensive summary of all important studies with intracoronary BMNCs implantation in AMI patients. Only larger randomized studies with similar study designs were included (13 studies, with a total of 811 patients involved). The median follow up time was 4 months. Two substantial results arise from this analysis: 1. intracoronary application of BMSCs in patients with ST-segment elevation myocardial infarction is safe. The combined clinical indicator including rates of deaths, rates of reinfarctions, hospitalisations due to heart failure and the need for revascularisation were similar between the actively treated groups and the controls and there were no records of higher rates of arrhythmias in patients who were given BMSCs. 2. Administration of BMSCs results in a moderate, but statistically significant LV systolic ejection fraction improvement by $2.99 \%(p=0.0007)$. Furthermore, a significant decrease in the left ventricular endsystolic volume by $4.74 \mathrm{ml}(\mathrm{p}=0.003)$ was demonstrated at the same time. A minor, insignificant decrease in the end-diastolic volume by $2.47 \mathrm{ml}(\mathrm{p}=0.13)$ also occurred. Compared to the control group, reduction in the infarction size by $3.51 \%$, was detected on SPECT. This was consistent with a previous metaanalysis of all studies, dealing with stem cells implantations in various cardiac clinical indications (14), as well as with a prior meta-analysis by Lipinski et al (35).

\section{Long-term results of the BMNCs therapy}

There are limited data on the long-term effects of the BMNCs therapy. According to one randomised study (36), initial positive effects on the LV function in the actively treated group receded in 18 months. In another study, after two years, the clinical course in terms of rates of hospitalisations for heart failure appeared better in patients who underwent intracoronary cell implantation (33). In 
a recent publication (37), analyzing long-term effects of the BMNCs transfer after MI in 62 patients, global as well as regional LV function was significantly improved at 12 months and a significant improvement was observed even after 5 years, while the LV function deteriorated in a non-randomised control group of 62 patients, who refused the procedure. This was consistent with a marked decrease of the infarction size in the treated patients, compared to the controls. Most interestingly, after almost 5 years of the follow-up, mortality was significantly lower in the treatment group. This is the first evidence that an initial functional effect of the BMNCs transfer could translate into a long-term benefit in hard clinical endpoints. The authors speculate that the above effects could result from decreased occurrence of heart failure through prevention of LV remodeling, as well as from lower incidence of arrhythmias, suggested by improvements in the heart rate variability and lower incidence of late potentials. In our study, the treatment group patients, although slightly disadvantaged by their older age and higher multi-vessel disease incidence rates, showed a tendency towards a lower incidence of the combined clinical endpoint, and a better subjective status according to NYHA classification.

\section{Remodeling after myocardial infarction}

Although difficult to quantify, the LV remodeling is a major factor, contributing to the development of infarct- related heart failure and death. It affects a substantial proportion of MI patients (38-40). However, among the post-MI patients, there is considerable heterogeneity considering responses to the $\mathrm{LV}$ remodeling (41). The infarction size seems to be the major determinant for unfavourable late remodeling (42). Therefore, it appears that the most severely affected patients with large infarctions and severe LV impairment could, theoretically, benefit from cellular therapy the most. Indeed, in the large REPAIR-AMI study, patients with the most severely impaired LV function showed the greatest improvement in LVEF following BMNSc infusion (33). The long-term left ventricular response to injury in patients with large necroses may differ from that in patients with small infarctions, as well as in patients with different MI locations and times to reperfusion. Differences in patient populations could be the reason for disparities in many of the reported study results. So far, in most of the studies the study populations consisted predominantly of patients with relatively mild LV impairments at baseline. Our study comprised a very homogenous group of patients with large first anterior MI, late reperfusion and significant LV impairment with LVEF which was considerably reduced compared to the previously published trials. Contrary to other studies, there were no significant differences in the course of the LV volume and functional changes by Month 4 between the actively treated patient group and the control group, however the long-term course was more favourable in the treated group. Early improvement in the LV function in both groups may reflect spontaneous healing and recovery, which occurs in more than $50 \%$ of post-MI patients in the "reperfusion era" (43). However, the late functional improvement is suggestive of a long-term favourable effect of the BMNCs implantation on the LV remodeling, which is known to be a longstanding process (44). The mechanisms, through which the BMNCs transfer could enhance
LV recovery and prevent or even reverse its remodeling, are poorly understood. Primary myocardial regeneration of new contractile tissue does not seem to be a likely mechanism, considering the small amount of cells $(1-5 \%)$ retained within the myocardium for 24-48 hours after their implantation (45). Although it has been advocated that adult peripheral CD34+ cells can transdifferentiate into cardiomyocytes, endothelial and smooth muscle cells in vivo (46), this potential was not confirmed by other studies (47, 48). Other mechanisms, possibly mediated by paracrine action of the implanted BMNCs, were proposed (49). These could include increased angiogenesis leading to improved blood supply to the ischemic region (50) or inhibition of cardiomyocyte apoptosis in the infarction border zone (5). Our data suggest that the effects of BMNCs implantation on LV remodeling could extend far beyond the immediate post-infarction period, possibly through improved healing and scar formation, as well through effects on contractile and vascular elements alone.

\section{Study limitations}

The present study has several limitations. Because no functional effects were demonstrated at Month 4 and because some early fatal cardiac complications were recorded in the actively treated patients, the study had been stopped early by the steering committee before the target number of patients was reached. Therefore, the number of patients in our study is too small to be able to draw definitive conclusions on the BMNCs therapy long-term effects. Although no causal relationship between the early complications in the actively treated patients and the BMNCs harvest was demostrated, inherent risks of this procedure in hemodynamicaly fragile, post-MI patients can not be completely ruled out.

The control group patients were not administered sham BMNCs infusions and sole effects of intermittent infarct- related artery occlusions on LV remodeling can not be completely excluded. Finaly, neither patients, nor their physicians were blinded to the treatment modality, therefore the clinical status assessments with respect to cell implantation were unreliable.

\section{Conclusion}

In our randomized study, no additional benefits of the BMNCs intracoronary infusion were observed when compared to the current reperfusion strategy in patients with large acute anterior myocardial infarction and late presentation, during the short- term follow up period. However, the long-term follow-up study of the BMNCs transplantation was associated with significant improvements in global LVEF. Although there were no differences in the early LV volume and function changes between the treatment group and the spontaneous healing control group, the long- term follow up outcomes suggest possible long-term protective effects against unfavourable LV remodeling. Although current data on the method's clinical efficacy are ambiguous and information on its mechanisms of action is controversial, the evidence of potential short-term and long-term positive effects on LV remodeling and repair is growing. The persisting uncertainty concerning clinical relevance of the stem cells implantation after MIs can only 
$220-227$

be resolved by large randomised clinical trials with hard clinical endpoints, which are currently conducted. Further progress in our understanding of the basic mechanisms of action, as well as further refinements in the cell selection and modes of application are clearly needed to enhance efficacy of the reparation process following cellular therapy, before the method can be recommended for widespread clinical use.

\section{References}

1. Bolognese L, Neskovic AN, Parodi G et al. Left Ventricular Remodeling After Primary Coronary Angioplasty: Patterns of Left Ventricular Dilation and Long-Term Prognostic Implications. Circulation 2002; 106 (18): 2351-2357.

2. Pfeffer MA, McMurray JJ, Velazquez EJ et al. Valsartan, captopril, or both in myocardial infarction complicated by heart failure, left ventricular dysfunction, or both. N Engl J Med 2003; 349 (20): 1893-1906.

3. Orlic D, Kajstura J, Chimenti S et al. Bone marrow cells regenerate infarcted myocardium. Nature. 2001; 410 (6829): 701-705.

4. Kawamoto A, Gwon HC, Iwaguro $\mathrm{H}$ et al. Therapeutic potential of ex vivo expanded endothelial progenitor cells for myocardial ischemia. Circulation 2001; 103 (5): 634-637.

5. Kocher AA, Schuster MD, Szaboles MJ et al. Neovascularization of ischemic myocardium by human bone-marrow-derived angioblasts prevents cardiomyocyte apoptosis, reduces remodeling and improves cardiac function. Nat Med 2001; 7 (4): 430-436.

6. Strauer BE, Brehm M, Zeus T et al. Repair of infarcted myocardium by autologous intracoronary mononuclear bone marrow cell transplantation in humans. Circulation 2002; 106 (15): 1913-1918.

7. Assmus B, Schachinger V, Teupe $\mathbf{C}$ et al. Transplantation of Progenitor Cells and Regeneration Enhancement in Acute Myocardial Infarction (TOPCARE-AMI). Circulation 2002; 106 (24): 3009-3017.

8. Wollert KC, Meyer GP, Lotz J et al. Intracoronary autologous bonemarrow cell transfer after myocardial infarction: the BOOST randomised controlled clinical trial. Lancet 2004; 364 (9429): 141-148.

9. Janssens S, Dubois C, Bogaert J et al. Autologous bone marrow-derived stem-cell transfer in patients with ST-segment elevation myocardial infarction: double-blind, randomised controlled trial. Lancet 2006; 367 (9505): 113-121.

10. Schachinger V, Erbs S, Elsasser A et al. Intracoronary bone marrowderived progenitor cells in acute myocardial infarction. N Engl J Med 2006; 355 (12): 1210-1221.

11. Lunde K, Solheim S, Aakhus S, Arnesen H, Abdelnoor M, Forfang K. Autologous stem cell transplantation in acute myocardial infarction: The ASTAMI randomized controlled trial. Intracoronary transplantation of autologous mononuclear bone marrow cells, study design and safety aspects. Scand Cardiovasc J 2005; 39 (3): 150-158.

12. Ge J, Li Y, Qian J et al. Efficacy of emergent transcatheter transplantation of stem cells for treatment of acute myocardial infarction (TCTSTAMI). Heart 2006; 92 (12): 1764-1767.

13. Caplice NM. The future of cell therapy for acute myocardial infarction. Nat Clin Pract Cardiovasc Med 2006; 3 Suppl 1: S129-132.

14. Abdel-Latif A, Bolli R, Tleyjeh IM et al. Adult bone marrow-derived cells for cardiac repair: a systematic review and meta-analysis. Arch Intern Med 2007; 167 (10): 989-997.
15. Halkin A, Singh M, Nikolsky E et al. Prediction of mortality after primary percutaneous coronary intervention for acute myocardial infarction: the CADILLAC risk score. J Am Coll Cardiol 2005; 45 (9): 1397-1405.

16. Penicka M, Horak J, Kobylka P et al. Intracoronary injection of autologous bone marrow-derived mononuclear cells in patients with large anterior acute myocardial infarction: a prematurely terminated randomized study. J Am Coll Cardiol 2007; 49 (24): 2373-2374.

17. Schiller NB, Shah PM, Crawford M et al. Recommendations for quantitation of the left ventricle by two-dimensional echocardiography. American Society of Echocardiography Committee on Standards, Subcommittee on Quantitation of Two-Dimensional Echocardiograms. J Am Soc Echocardiogr 1989; 2 (5): 358-367.

18. Araszkiewicz A, Lesiak M, Grajek S, Prech M, Cieslinski A. Relationship between tissue reperfusion and postinfarction left ventricular remodelling in patients with anterior wall myocardial infarction treated with primary coronary angioplasty. Kardiol Pol 2006; 64 (4): 383-388; discussion 389-390.

19. Orlic D. Stem cell repair in ischemic heart disease: an experimental model. Int J Hematol 2002; 76 Suppl 1: 144-145.

20. Beltrami AP, Barlucchi L, Torella $D$ et al. Adult cardiac stem cells are multipotent and support myocardial regeneration. Cell 2003; 114 (6): 763-776.

21. Tomita S, Mickle DA, Weisel RD et al. Improved heart function with myogenesis and angiogenesis after autologous porcine bone marrow stromal cell transplantation. J Thorac Cardiovasc Surg 2002; 123 (6): $1132-1140$.

22. Moelker AD, Baks T, van den Bos EJ et al. Reduction in infarct size, but no functional improvement after bone marrow cell administration in a porcine model of reperfused myocardial infarction. Eur Heart J 2006; 27 (24): 3057-3064.

23. Badorff C, Brandes RP, Popp R et al. Transdifferentiation of bloodderived human adult endothelial progenitor cells into functionally active cardiomyocytes. Circulation 2003; 107 (7): 1024-1032.

24. Tse HF, Yiu KH, Lau CP. Bone marrow stem cell therapy for myocardial angiogenesis. Curr Vasc Pharmacol 2007; 5 (2): 103-112.

25. Aviles FF, San Roman JA, Garcia Frade J et al. [Intracoronary stem cell transplantation in acute myocardial infarction]. Rev Esp Cardiol 2004; 57 (3): 201-208.

26. Stamm C, Westphal B, Kleine HD et al. Autologous bone-marrow stem-cell transplantation for myocardial regeneration. Lancet 2003; 361 (9351): 45-46.

27. Kang HJ, Kim HS, Zhang SY et al. Effects of intracoronary infusion of peripheral blood stem-cells mobilised with granulocyte-colony stimulating factor on left ventricular systolic function and restenosis after coronary stenting in myocardial infarction: the MAGIC cell randomised clinical trial. Lancet 2004; 363 (9411): 751-756.

28. Meluzin J, Mayer J, Groch $\mathbf{L}$ et al. Autologous transplantation of mononuclear bone marrow cells in patients with acute myocardial infarction: the effect of the dose of transplanted cells on myocardial function. Am Heart J 2006; 152 (5): 975 e9-15.

29. Janssens S, Theunissen K, Boogaerts M, Van de Werf F. Bone marrow cell transfer in acute myocardial infarction. Nat Clin Pract Cardiovasc Med 2006; 3 Suppl 1: S69-72.

30. Hirsch A, Nijveldt R, van der Vleuten PA et al. Intracoronary infusion of autologous mononuclear bone marrow cells in patients with acute myocardial infarction treated with primary PCI: Pilot study of the multicenter HEBE trial. Catheter Cardiovasc Interv 2008; 71 (3): 273-281. 
31. Charwat S, Gyongyosi M, Lang I et al. Role of adult bone marrow stem cells in the repair of ischemic myocardium: current state of the art. Exp Hematol 2008; 36 (6): 672-680.

32. Janssens $\mathbf{S}$. Stem cell therapy in acute myocardial infarction. Acta Clin Belg 2007; 62 (5): 342-734.

33. Schachinger V, Erbs S, Elsasser A et al. Improved clinical outcome after intracoronary administration of bone-marrow-derived progenitor cells in acute myocardial infarction: final 1-year results of the REPAIR-AMI trial. Eur Heart J 2006; 27 (23): 2775-2783.

34. Martin-Rendon E, Brunskill SJ, Hyde CJ, Stanworth SJ, Mathur A, Watt SM. Autologous bone marrow stem cells to treat acute myocardial infarction: a systematic review. Eur Heart J 2008; 29 (15): 1807-1818.

35. Lipinski MJ, Biondi-Zoccai GG, Abbate A et al. Impact of intracoronary cell therapy on left ventricular function in the setting of acute myocardial infarction: a collaborative systematic review and meta-analysis of controlled clinical trials. J Am Coll Cardiol 2007; 50 (18): 1761-1767.

36. Meyer GP, Wollert KC, Lotz $\mathbf{J}$ et al. Intracoronary bone marrow cell transfer after myocardial infarction: eighteen months' follow-up data from the randomized, controlled BOOST (BOne marrOw transfer to enhance STelevation infarct regeneration) trial. Circulation 2006; 113 (10): 1287-1294.

37. Yousef M, Schannwell CM, Kostering M, Zeus T, Brehm M, Strauer BE. The BALANCE Study: clinical benefit and long-term outcome after intracoronary autologous bone marrow cell transplantation in patients with acute myocardial infarction. J Am Coll Cardiol 2009; 53 (24): 2262-2269.

38. Pfeffer MA, Braunwald E. Ventricular remodeling after myocardial infarction. Experimental observations and clinical implications. Circulation 1990; 81 (4): 1161-1172.

39. Sutton MSJ, Pfeffer MA, Moye L et al. Cardiovascular Death and Left Ventricular Remodeling Two Years After Myocardial Infarction: Baseline Predictors and Impact of Long-term Use of Captopril: Information From the Survival and Ventricular Enlargement (SAVE) Trial. Circulation 1997; 96 (10): 3294-3299.

40. Sheiban I, Fragasso G, Rosano GM et al. Time course and determinants of left ventricular function recovery after primary angioplasty in patients with acute myocardial infarction. J Am Coll Cardiol 2001; 38 (2): 464-471.
41. Giannuzzi P, Temporelli PL, Bosimini E et al. Heterogeneity of left ventricular remodeling after acute myocardial infarction: results of the Gruppo Italiano per lo Studio della Sopravvivenza nell'Infarto Miocardico-3 Echo Substudy. Am Heart J 2001; 141 (1): 131-138.

42. Sutton MGSJ, Sharpe N. Left Ventricular Remodeling After Myocardial Infarction : Pathophysiology and Therapy. Circulation 2000; 101 (25): 2981-2988.

43. Solomon SD, Glynn RJ, Greaves S et al. Recovery of ventricular function after myocardial infarction in the reperfusion era: the healing and early afterload reducing therapy study. Ann Intern Med 2001; 134 (6): 451-458.

44. Hole T, Vegsundvag JA, Morstol TH, Skaerpe T. Early changes in left ventricular volume and function are predictors for long-term remodeling in patients with acute transmural myocardial infarction and preserved systolic function. J Am Soc Echocardiogr 2003; 16 (6): 630-637.

45. Penicka M, Widimsky P, Kobylka P, Kozak T, Lang O. Images in cardiovascular medicine. Early tissue distribution of bone marrow mononuclear cells after transcoronary transplantation in a patient with acute myocardial infarction. Circulation 2005; 112 (4): e63-65.

46. Yeh ET, Zhang S, Wu HD, Korbling M, Willerson JT, Estrov Z. Transdifferentiation of human peripheral blood CD34+-enriched cell population into cardiomyocytes, endothelial cells, and smooth muscle cells in vivo. Circulation 2003; 108 (17): 2070-2073.

47. Balsam LB, Wagers AJ, Christensen JL, Kofidis T, Weissman IL, Robbins RC. Haematopoietic stem cells adopt mature haematopoietic fates in ischaemic myocardium. Nature 2004; 428 (6983): 668-673.

48. Murry CE, Soonpaa MH, Reinecke $\mathbf{H}$ et al. Haematopoietic stem cells do not transdifferentiate into cardiac myocytes in myocardial infarcts. Nature 2004; 428 (6983): 664-668.

49. Korf-Klingebiel M, Kempf T, Sauer T et al. Bone marrow cells are a rich source of growth factors and cytokines: implications for cell therapy trials after myocardial infarction. Eur Heart J 2008; 29 (23): 2851-2858.

50. Boyle AJ, Whitbourn R, Schlicht $\mathbf{S}$ et al. Intra-coronary high-dose $\mathrm{CD} 34+$ stem cells in patients with chronic ischemic heart disease: a 12-month follow-up. Int J Cardiol 2006; 109 (1): 21-27.

Received April 5, 2010. Accepted December 13, 2011. 